University of South Carolina

Scholar Commons

3-1-2007

\title{
A Reconfigurable Stacked Microstrip Patch Antenna for Satellite and Terrestrial Links
}

\author{
Mohammod Ali \\ University of South Carolina - Columbia, alimo@engr.sc.edu
}

Abu T.M. Sayem

Motorola, Inc., abu.sayem@motorola.com

Vijay K. Kunda

Sun Micro Systems, vijay.kunda@sun.com

Follow this and additional works at: https://scholarcommons.sc.edu/elct_facpub

Part of the Electrical and Computer Engineering Commons

\section{Publication Info}

Published in IEEE Transactions on Vehicular Technology, Volume 56, 2007, pages 426-435.

http://ieeexplore.ieee.org/xpl/Recentlssue.jsp?punumber=25

(C) 2007 by IEEE

This Article is brought to you by the Electrical Engineering, Department of at Scholar Commons. It has been accepted for inclusion in Faculty Publications by an authorized administrator of Scholar Commons. For more information, please contact digres@mailbox.sc.edu. 


\title{
A Reconfigurable Stacked Microstrip Patch Antenna for Satellite and Terrestrial Links
}

\author{
Mohammod Ali, Senior Member, IEEE, Abu T. M. Sayem, Student Member, IEEE, and Vijay K. Kunda
}

\begin{abstract}
A reconfigurable stacked microstrip patch antenna is proposed. The antenna operates at an upper frequency $f_{\mathrm{u}}$ with a broadside pattern, 7.5-dBi right-hand circularly polarized gain, and $15.8 \%$ bandwidth. At a lower frequency $f_{1}$, the antenna operates as a planar inverted-F antenna $(7.3 \%$ bandwidth and $3.9-\mathrm{dBi}$ peak gain) with the main beam directed close to the horizon. Switching between the two regimes of operation is achieved using p-i-n diodes. Antenna operation in the upper frequency band is suitable for low-earth-orbit or medium-earth-orbit satellite communications, and in the lower frequency band, the antenna is useful for terrestrial land-mobile or other wireless applications.
\end{abstract}

Index Terms-Reconfigurable antenna, satellite link, stacked patch antenna, terrestrial link.

\section{INTRODUCTION}

$\mathbf{R}$ ECONFIGURABLE antennas are becoming more and more important in defense and commercial wireless applications, since with such antennas, a single aperture can be used to support multiple functions at multiple frequency bands. This will result in a significant reduction in antenna size and cost. An antenna can be reconfigured using p-i-n diode or transistor switches.

In [1], a microstrip antenna was reconfigured using MEMS switches. The patch geometry was subdivided, and the MEMS switches were positioned at different locations of the antenna to increase or decrease its size, thereby changing the antenna resonant frequency. A MEMS reconfigurable Vee antenna was proposed in [2], where the beam was steered or shaped using microactuators. A reconfigurable patch antenna with switchable slots using the p-i-n diodes was introduced in [3]. Switching using $\mathrm{p}-\mathrm{i}-\mathrm{n}$ diodes helped achieve polarization diversity. A planar VHF reconfigurable slot antenna was proposed by Peroulis et al. [4], where a resonant slot antenna was loaded with multiple $\mathrm{p}-\mathrm{i}-\mathrm{n}$ diode switches to achieve a frequency switching from 550 to $900 \mathrm{MHz}$. Stacked reconfigured bow-tie elements were proposed by Bernhard et al. [5] for space-based radar applications. These wideband elements were proposed in conjunction with the MEMS switches for reconfigurability. Yang and Rahmat-Samii [3] also proposed a p-i-n diode

Manuscript received April 11, 2004; revised July 28, 2005, March 6, 2006, and March 23, 2006. This work was supported in part by the National Science Foundation (NSF) Career Award ECS-0237783. The review of this paper was coordinated by Prof. R. Janaswamy.

M. Ali and A. T. M. Sayem are with the Department of Electrical Engineering, University of South Carolina, Columbia, SC 29208 USA (e-mail: alimo@ engr.sc.edu; sayem@engr.sc.edu).

V. K. Kunda is with the Sun Micro Systems, Burlington, MA 01803 USA (e-mail: Vijay.Kunda@Sun.com).

Digital Object Identifier 10.1109/TVT.2007.891412 switched reconfigurable patch for circular polarization diversity in [6]. The Georgia Tech Research Institute proposed a reconfigurable aperture controlled by a p-i-n diode or FET switches in [7]. A single turn square spiral antenna was reconfigured for frequency and pattern in [8] for operation at 3.7 and $6 \mathrm{GHz}$. Another reconfigurable antenna was proposed in [9] where the microstrip antenna was made to be out of plane due to plastic deformation magnetic actuation. A mutlielement miniature antenna was proposed in [10], which can operate at multiple frequency bands using the MEMS switches. In [11] and [12], two examples of shorting-strap tunable planar inverted-F antennas (PIFAs) are given, where the antenna operating frequency is switched by turning the shorting straps "on" or "off."

In this paper, we present a reconfigurable stacked square microstrip patch antenna which provides a high-gain directional pattern at one frequency band (say $f_{\mathrm{u}}$ ) and a low-gain omnidirectional-type pattern at another (say $f_{\mathrm{l}}$ ). At $f_{\mathrm{u}}$, the antenna can also support a right-hand circular polarization (RHCP) with a good axial ratio to support a satellite communication system. One particular example for the upper frequency directional application can be a vehicular satellite terminal antenna for the low-earth-orbit or medium-earth-orbit systems operating around $2 \mathrm{GHz}$. The lower frequency linearly polarized application can support terrestrial land mobile radio application. The typical ratio between $f_{\mathrm{u}}$ and $f_{\mathrm{l}}$ is about three. Reconfigurable operation can be achieved using p-i-n diode, FET, or MEMS switches. Our prototype antenna was built and tested with the $\mathrm{p}-\mathrm{i}-\mathrm{n}$ diode switches.

The primary advantage of the proposed reconfigurable antenna lies in its ability to support two separate applications at two different frequency bands with distinctly different radiation patterns, gain, and polarization characteristics using a single radiating aperture. If instead two separate antennas are used, they must be placed in two separate locations requiring twice as much surface area. Also, in order to ensure a minimal cosite interference between the two antennas, they have to be placed at a sufficient distance from each other, which will require additional space. One minor limitation of the proposed reconfigurable antenna lies in its choice of switches. The p-i-n diode switch used for the stacked patch mode of operation $\left(f_{\mathrm{u}}\right)$ has an insertion loss of only $0.4 \mathrm{~dB}$ at $1.75 \mathrm{GHz}$. The effect of this loss is minimal on the peak gain of the antenna. Similarly, the insertion loss of the switch used for the $688-\mathrm{MHz}\left(f_{\mathrm{l}}\right)$ PIFA is $0.7 \mathrm{~dB}$, which will reduce the peak gain of the antenna from 4.6 to $3.9 \mathrm{dBi}$. If further improvement in performance is required, high-performance MEMS switches with insertion loss of the order of $0.16 \mathrm{~dB}$ can be used [13]. 


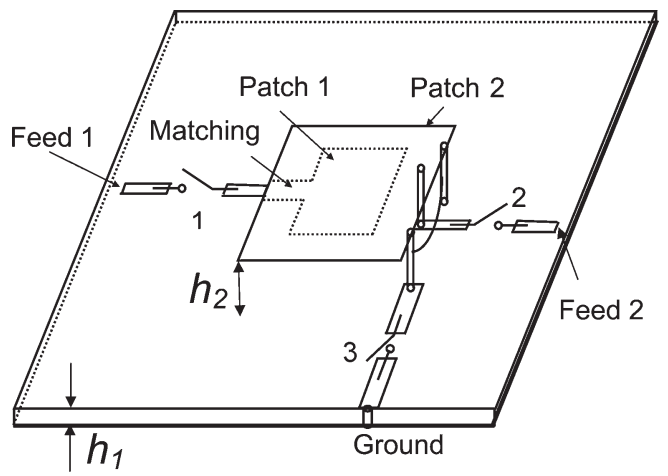

Fig. 1. Schematic diagram of the proposed reconfigurable antenna.

The proposed reconfigurable stacked patch antenna is a good candidate for vehicular communication where the antenna can be mounted on the roof of a vehicle and enclosed within a radome. The feeding of the antenna can be achieved by conventional through the roof connection or by routing a coaxial cable through the door-jam. Antenna feeding may also be achieved by a noncontact proximity capacitive coupling through the windshield glass if a broadband or dual-band coupler can be designed to achieve that. Generally, such couplers suffer from high losses. The high-gain circularly polarized beam is an ideal candidate for vehicle mounted satellite communication systems, while the moderate-gain linearly polarized nearly omnidirectional beam is suitable for UHF land mobile radio application. In cases where the ratio of $f_{\mathrm{u}} / f_{1}$ needs to be different from the above, additional shorting pins can be used to tune the antenna at some other frequencies [11], [12].

\section{ANTENNA DESIGN}

The geometry of the proposed antenna is shown in Fig. 1. It consists of two square patches, patch 1 and patch 2. Patch 1 is printed on RO4003 substrate from Rogers corporation $\left(h_{1}=\right.$ $\left.1.5 \mathrm{~mm}, \varepsilon_{r 1}=3.38, \tan \delta=0.0027\right)$. Patch 2 is located on top of a Rohacell foam substrate with thickness $h_{2}$ and dielectric constant $\varepsilon_{r 2}=1.04$.

The proposed design consists of two feeds and two shorting pins, all of which are electronically controlled by the p-i-n diode switches. Switch 1 controls feed 1 and, hence, the stacked patch mode of operation, while switches 2 and 3 control the PIFA mode of operation. Note that feed 2 connects to a vertical wire that feeds the top patch. Also, there are two vertical wires on the two sides of feed 2. These are called the shorting pins. The shorting pins are connected to each other using a wire. This way, only one switch is needed to control them. For instance, when feed 1 is activated, feed 2 and the shorting pins are "off," and the antenna operates as a stacked microstrip patch antenna. Thus, patch 2 is not electrically connected to feed 2 or ground. Since patch 1 is fed by feed 1 , and patch 2 is electromagnetically coupled to patch 1 , the whole geometry becomes a stacked microstrip patch.

In contrast, when feed 1 is "off" and feed 2 and the shorting pins are "on," patch 1 is disconnected from feed 1 , while patch 2 is connected to feed 2 and its associated shorting pins. In this

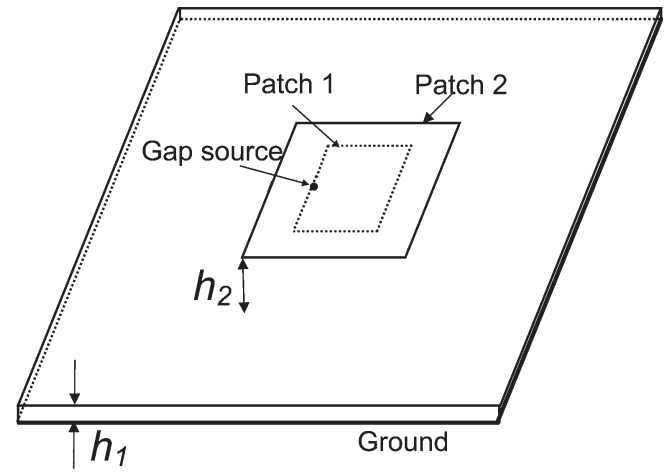

Fig. 2. Stacked patch drawing corresponding to the HFSS model.

scenario, patch 2 is essentially a PIFA suitable for operation at a lower frequency $\left(f_{1}\right)$ by virtue of being short-circuited at two ends. In this regime of operation, the antenna main beam is directed closely toward the horizon suitable for terrestrial communications.

\section{RESULTS}

\section{A. Stacked Patch Design at $2 \mathrm{GHz}$}

The focus of this paper is to design a reconfigurable stacked microstrip patch antenna that can operate at two frequency bands and satisfy different pattern, gain, and polarization requirements.

To design our stacked microstrip patch antenna at around $2 \mathrm{GHz}$, first, we conducted a parametric study using High Frequency Structure Simulator (HFSS) [14]. The design was centered at around $2 \mathrm{GHz}$ because there are several satellite applications in the vicinity of that frequency. No attempt was made to design for any particular application. As indicated, the primary substrate chosen was 1.5 -mm-thick $\mathrm{RO} 4003$ because of convenience and availability of the material in our lab. The design principles described in this paper apply equally well for other low dielectric constant substrates such as Duroid 5880. There has been a considerable research activity in the realm of stacked microstrip patch antennas with various different feeding schemes. Examples of some recent works appear in [15]-[19].

The initial dimensions of our stacked patch antenna and the height between them were simple estimates from the author's previous industrial research experience. The antenna parameters selected were length of patch $1, L 1=41 \mathrm{~mm}$, length of patch $2, L 2=60 \mathrm{~mm}$, and the size of the ground plane was 130 by $130 \mathrm{~mm}\left(\sim 0.9 \lambda_{0}\right.$ by $\left.0.9 \lambda_{0}\right)$. Antenna parameters such as the foam thickness $\left(h_{2}\right)$ and antenna lengths ( $L 1$ and $\left.L 2\right)$ were modified. An ideal lumped gap source with $50-\Omega$ impedance was considered to feed the antenna. The lumped feed was positioned in the middle of one edge of patch 1 , which excited the fields between the patch and the ground plane (see Fig. 2). If a $50-\Omega$ microstrip transmission line is used to feed patch 1 , it will see the same impedance calculated using this method. The actual microstrip line feed was not implemented in the model simply to find the impedance of the antenna at its feed point not at a distance from it along the line. 


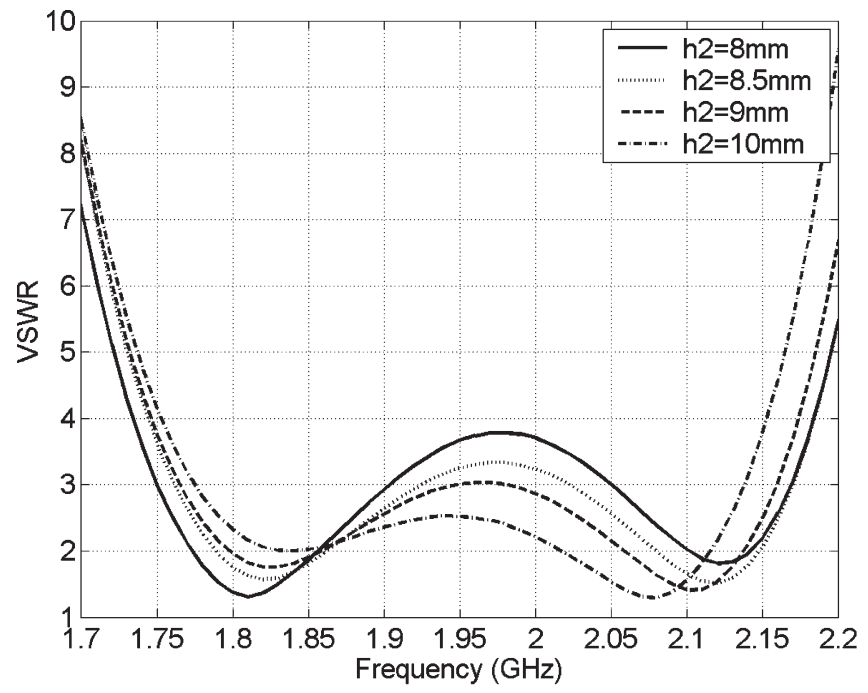

(a)

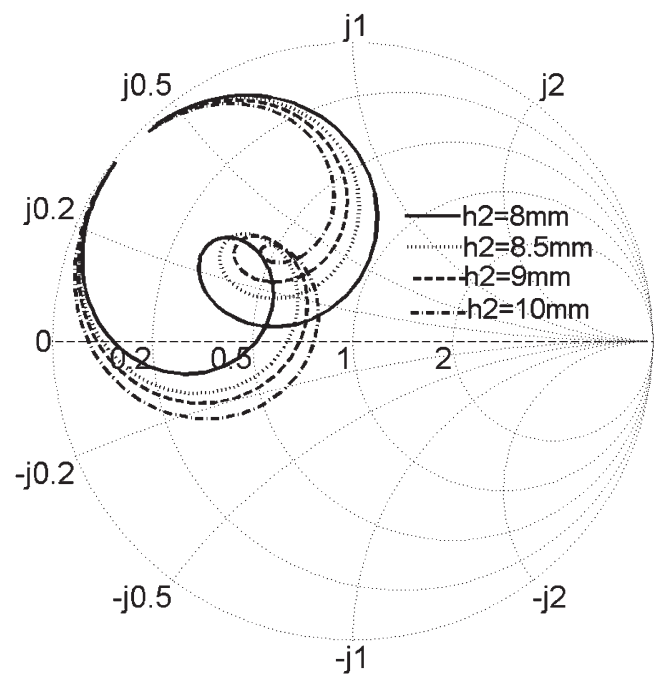

(b)

Fig. 3. Computed (a) VSWR and (b) input impedance versus frequency with the height between the patches $(h 2)$ as the parameter. Other antenna parameters are $L 1=41 \mathrm{~mm}, L 2=60 \mathrm{~mm}, h_{1}=1.5 \mathrm{~mm}, \varepsilon_{r 1}=3.38$, and $\varepsilon_{r 2}=1.04$.

1) Effect of Foam Substrate Thickness (h2): Since the stacked patch operation depends on the establishment of an effective coupling mechanism between the driven patch (patch 1) and the top radiating patch (patch 2), the thickness of substrate2 ( $h 2$ ) should have an important role on the antenna impedance tuning. This is studied in Fig. 3. It is observed that as $h 2$ increases, the knot size of the impedance locus decreases, and the impedance becomes more inductive. Increasing $h 2$ from 8 to $10 \mathrm{~mm}$ helps reduce the midband voltage standing wave ratio (VSWR). Traditionally, a thick foam layer is used to achieve a wideband operation. However, in this paper, we focused on restricting the overall thickness of the antenna. Therefore, we selected $h 2=8.5 \mathrm{~mm}$.

2) Length of Patch 1 (L1): The sensitivity of the antenna impedance as a function of the length $(L 1)$ of the driven patch (patch 1) is studied. These results are shown in Fig. 4(a), from which it is clear that as $L 1$ is increased, antenna resonant frequencies and VSWR decrease. The decrease in resonant

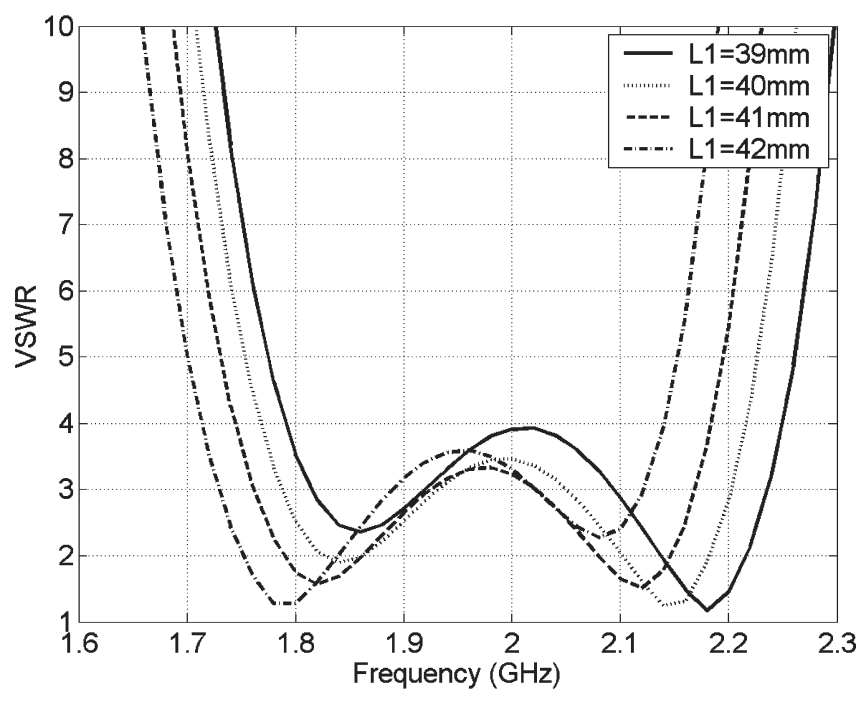

(a)

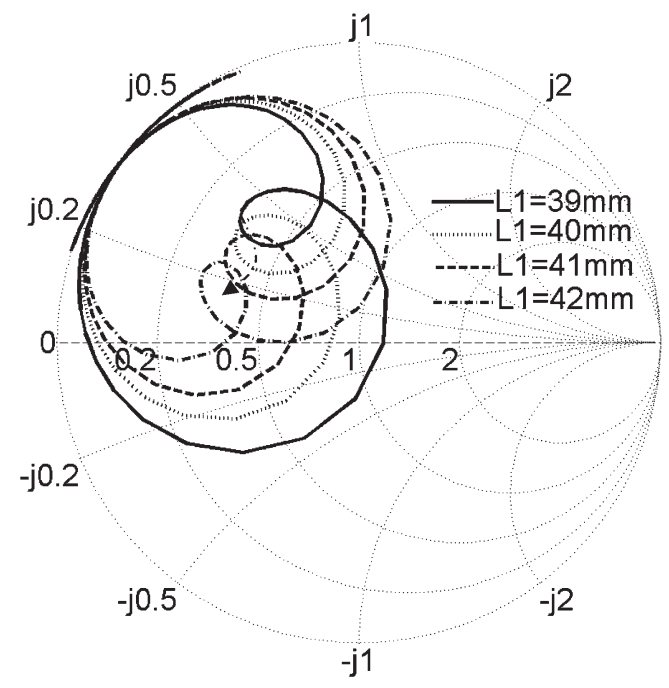

(b)

Fig. 4. (a) VSWR and (b) input impedance versus frequency with the length (L1) of driven patch (patch1) as the parameter.

frequencies is clearly attributable to the increase in antenna length. The VSWR decreases because the match is better which can be confirmed from the impedance plots shown in Fig. 4(b).

3) Length of Patch 2(L2): The influence of the length of the top patch (patch 2) is studied in Fig. 5. Comparing the smith chart plots of Figs. 4(b) and 5(b), it is evident that an increase in $L 1$ moves the impedance locus in a clockwise fashion as indicated by the arrows, while an increase in $L 2$ moves the impedance locus in a counterclockwise fashion. The first of the two scenarios is analogous to adding a shunt capacitor to the antenna input impedance, while the second clearly indicates the influence of a shunt inductor. Thus, since the influence of $L 1$ and $L 2$ is generally opposite, a reasonable middle ground can be reached.

4) Selection of a Matching Element ( $d$ and $W_{0}$ ): From the above studies, it is clear that with the given dimensions, a 2:1 VSWR bandwidth is not readily achievable with the substrate heights chosen. Of course, if $h 1$ and $h 2$ are varied 


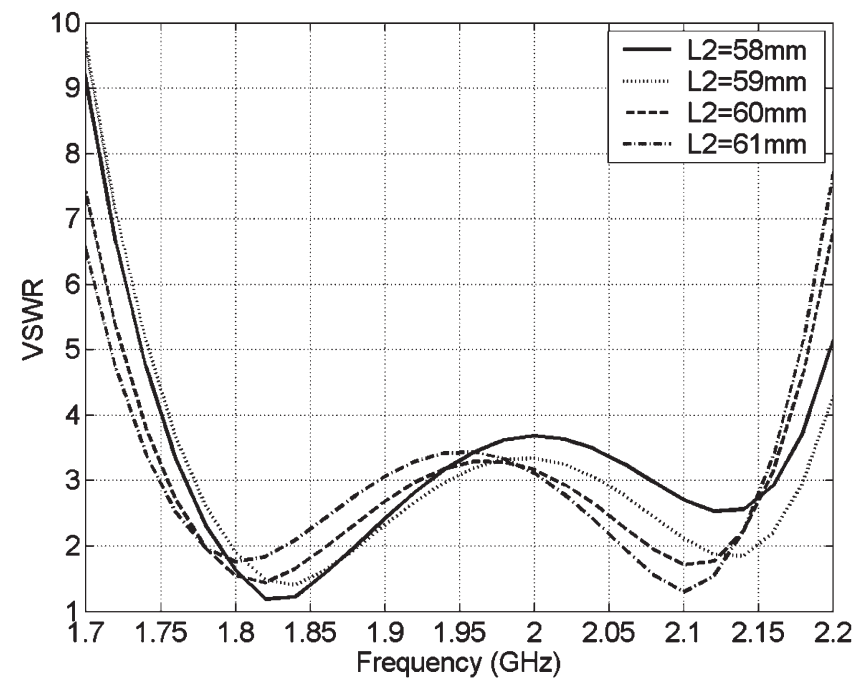

(a)
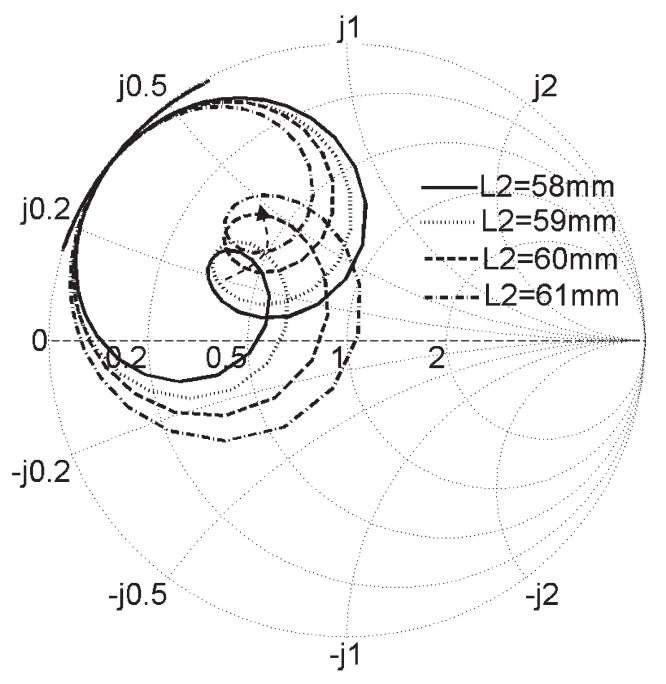

(b)

Fig. 5. (a) VSWR and (b) input impedance versus frequency with the length $(L 2)$ of the top patch (patch2) as the parameter.

more freely, a matching can be obtained. For this specific case, we consider adding a small matching element. Observing the impedance plot in Fig. 5(b) with $L 1=40 \mathrm{~mm}, L 2=60 \mathrm{~mm}$, and $h 2=8.5 \mathrm{~mm}$, it can be concluded that the impedance can be matched with the help of a shunt capacitor. From the stepped impedance filter theory, it is well known that a small section $(d \ll \lambda)$ of a low impedance line (see Fig. 6) behaves as a shunt capacitor [20]. We considered a $34-\Omega$ characteristic impedance line $\left(W_{0}=6 \mathrm{~mm}\right)$ to design the matching element. Other low impedance line can also be used. Varying the length of the matching section $(d)$ resulted in the impedance characteristics shown in Fig. 7(b). From the VSWR performance, the antenna operating bandwidth extends from 1.8 to $2.12 \mathrm{GHz}$ within $2: 1$.

\section{B. Stacked Patch Performance}

1) Patch Bandwidth (Without Any Switch, Vertical PIFA Feed, or Shorting Pin Wires): Based on the design just de-

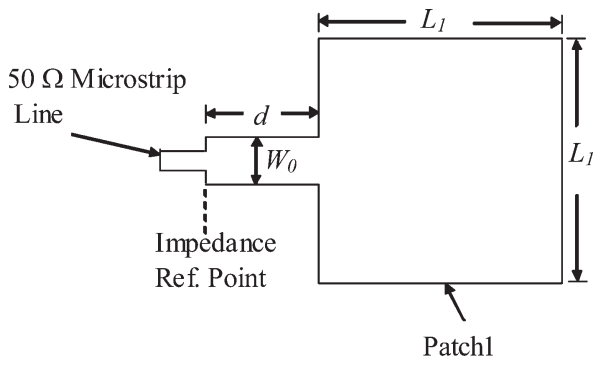

Fig. 6. Low-impedance microstrip matching section of length $d$ and width $W_{0}$.

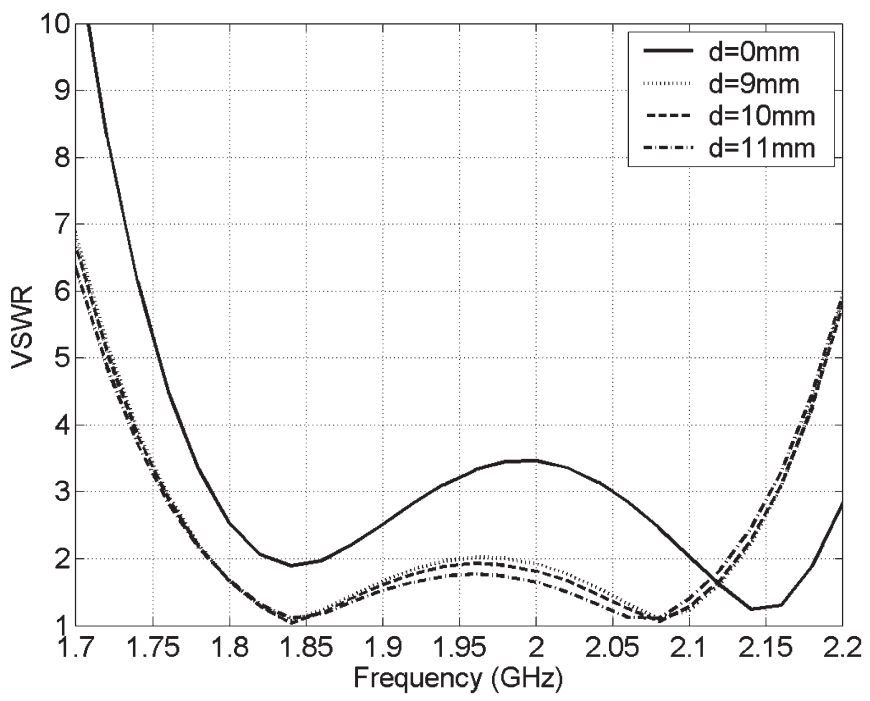

(a)

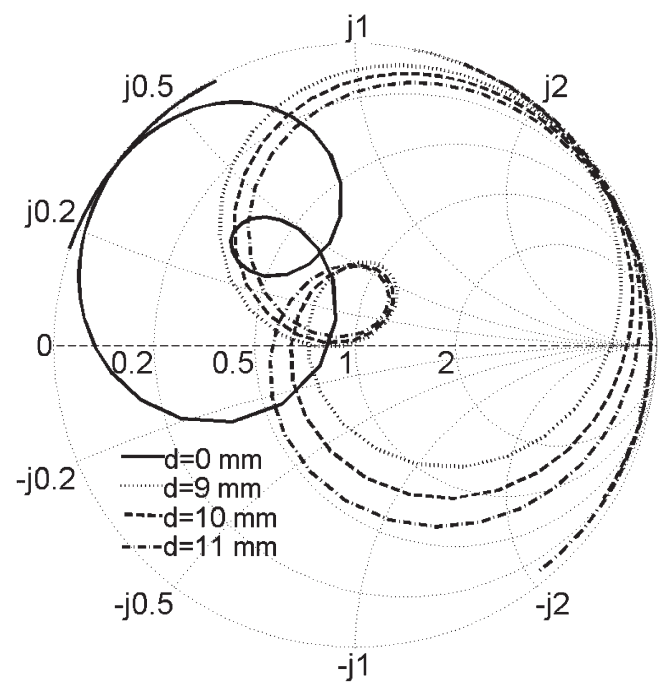

(b)

Fig. 7. Simulated (a) VSWR and (b) input impedance versus frequency with the length of the matching section $(d)$ as a parameter.

scribed, a prototype stacked microstrip patch antenna was fabricated without the switches, control circuits, and the vertical feed and shorting pin wires. The antenna (patch 1) consisted of a single-sided microstrip line feed with the low impedance 


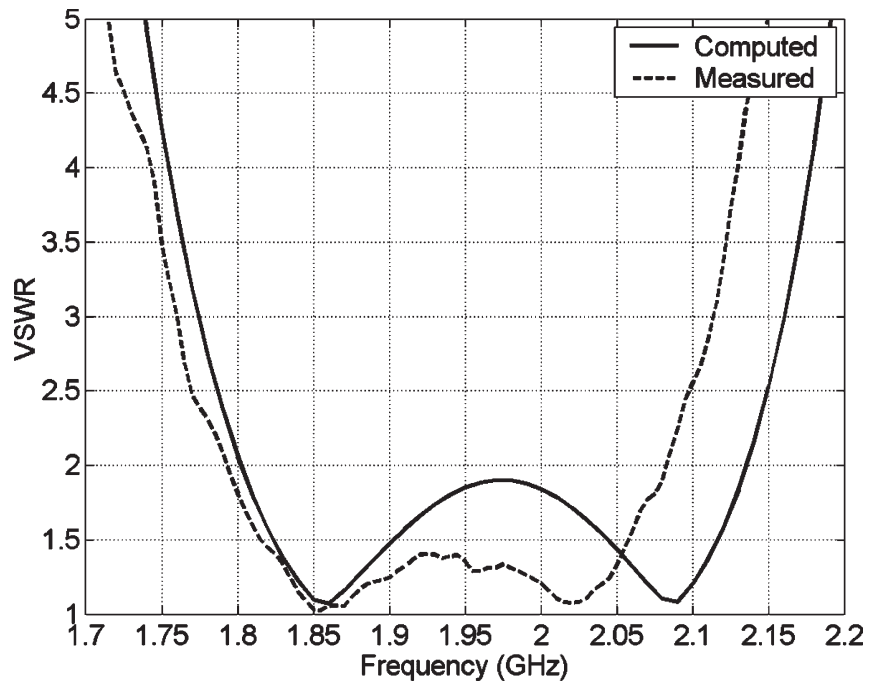

Fig. 8. VSWR versus frequency for the $2-\mathrm{GHz}$ stacked patch $(1.8-2.15 \mathrm{GHz})$.

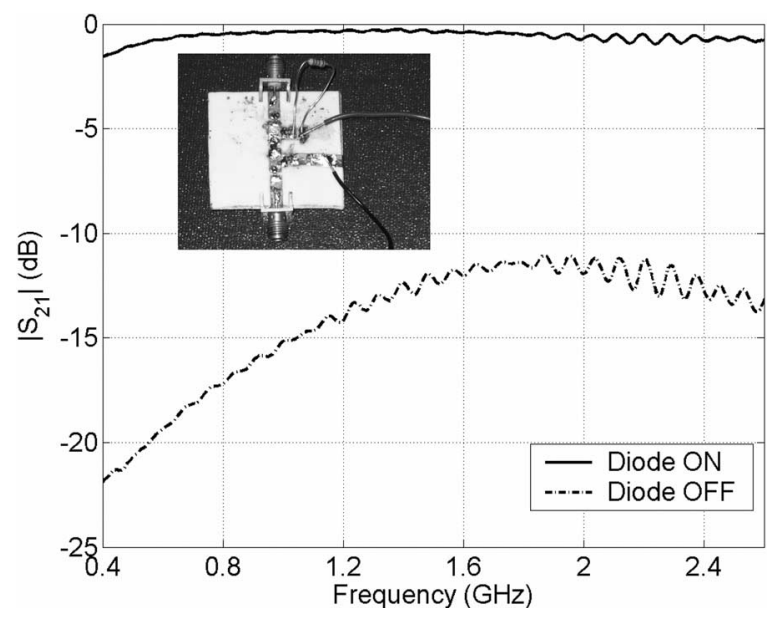

Fig. 9. Measured insertion loss and isolation for the HSMP 389B p-i-n diode switch.

matching section $\left(d=10 \mathrm{~mm}, W_{0}=6 \mathrm{~mm}\right)$ shown in Fig. 6 . The top patch (patch 2) was glued on an 8.5-mm-thick Rohacell foam and placed on patch 1 . Computed and measured VSWR data for this case are shown in Fig. 8. The agreement between the data is good. Computed and measured bandwidths are 340 and $290 \mathrm{MHz}$, respectively.

2) PIN Diode Switch Characteristics: The p-i-n diode switches were used to change the antenna operating mode from the stacked patch regime of operation to the PIFA regime of operation. HSMP 389B diodes from Agilent Corporation [21] were used. Measured switch insertion loss and isolation data are shown in Fig. 9. At $600 \mathrm{MHz}$, the insertion loss is about $0.7 \mathrm{~dB}$, and the isolation is $20 \mathrm{~dB}$, while those at $2 \mathrm{GHz}$ are around 0.4 and $12 \mathrm{~dB}$, respectively. The switch insertion loss and isolation are dominated by the ON-state resistance and OFF-state capacitance of the diode. If an increased isolation is required, very low capacitance diode or transistor switches should be used.

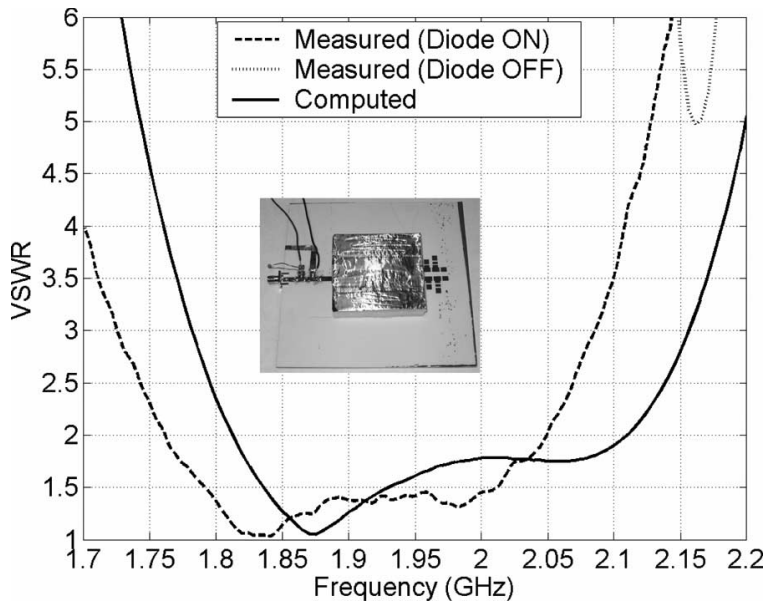

Fig. 10. VSWR versus frequency for the stacked patch with the switch and the control circuit. PIFA vertical feed, shorting pin, and control circuits are not connected.

3) Patch Bandwidth (With Switch for Patch Mode but Without Switch, Vertical PIFA Feed or Shorting Pin Wires): Next, the switch and control circuit to control the patch mode were connected. Thus, "feed 1" in Fig. 1 can now be activated and deactivated. The PIFA mode vertical wires, shorting pins, and control circuits were not connected at this time. The measured VSWR data for cases when switch 1 (referring to Fig. 1) was turned "on" and "off" are shown in Fig. 10. An inset photograph shows that the patch mode switch circuit on the left is complete and ready for measurement. The computed VSWR data correspond to a model where the diode and capacitors are considered short and the inductors as open. Apparently, the measured VSWR curve shifted about $50 \mathrm{MHz}$ lower in frequency. The overall bandwidth remained the same. The antenna does not operate when the diode is "off," as expected.

4) Patch Bandwidth (With All Switches, Vertical PIFA Feed, and Shorting Pin Wires, and Control Circuits): Final measurement of the patch mode performance was conducted in the presence of the vertical feed, shorting pin wires, and control circuits of the PIFA mode. However, the measurements were conducted with the PIFA switching circuitry biased "off" while the patch mode switch circuitry biased "on." The measured VSWR characteristics for this case are shown in Fig. 11(b). Throughout the frequency range, the VSWR was found to be higher than $2: 1$. Observing the impedance characteristics [Fig. 11(a) labeled "before tuning"], we inferred that the matching element needed to be adjusted to provide more shunt capacitance. By making the width of the matching element $12 \mathrm{~mm}$ instead of $6 \mathrm{~mm}$ resulted in the impedance and VSWR plots labeled "after tuning." Clearly, the PIFA vertical feed, shorting pin wires, and the connection pads have affected the patch mode VSWR. After tuning, the antenna operating frequency shifted $100 \mathrm{MHz}$ lower as compared to the characteristic shown in Fig. 10. The bandwidth of the antenna is nearly unchanged (15.8\% within $2: 1$ VSWR).

5) Radiation Pattern, Gain, and Axial Ratio: Antenna radiation characteristics were simulated using the HFSS. Since it is difficult to model diodes and surface mount ceramic chip 


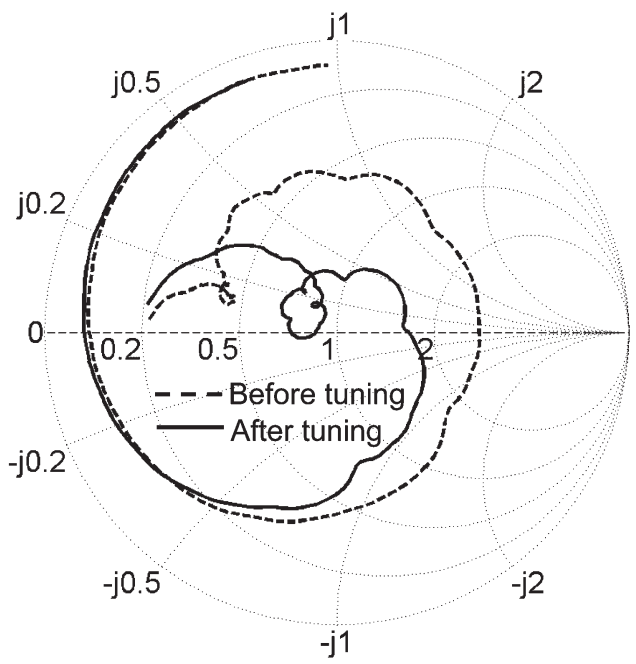

(a)

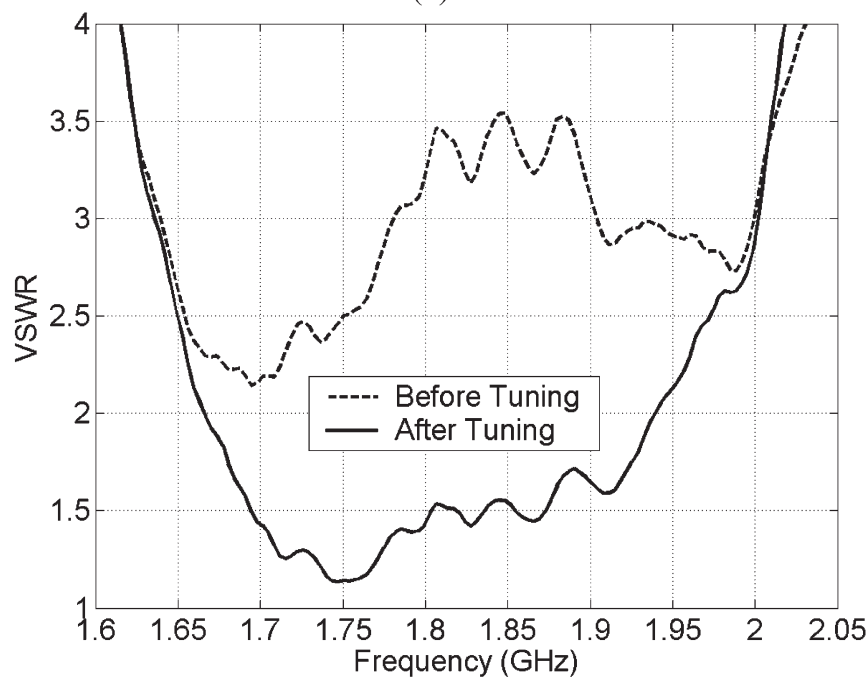

(b)

Fig. 11. Measured (a) impedance and (b) VSWR for the stacked patch antenna with the "patch" mode switch turned "on." PIFA vertical feed, shorting pins, and switches are connected, but bias is turned "off."

capacitors, inductors, and resistors in a full-wave solver, we considered a representative model shown in Fig. 12. In this model, the diodes are considered as short circuits when they are "on" and open circuits when they are "off." Thus, for the stacked patch mode of operation, the PIFA mode diodes are assumed open. The capacitors are considered shorts while the inductors are considered open. As illustrated in Fig. 12, there were three vertical wires with a diameter of $1 \mathrm{~mm}$ connected to the top patch. The wires were connected to small rectangular pads measuring 0.5 by $2 \mathrm{~mm}$ on the RO4003 substrate. To achieve circular polarization, two feeds were considered having $0^{\circ}$ and $90^{\circ}$ phases, respectively.

Computed radiation pattern data at $1.95 \mathrm{GHz}$ for the stacked patch mode are shown plotted in Fig. 13. The patterns (RHCP) without the PIFA vertical feed and shorting pin wires and connecting pads show excellent broadside beams and crosspolarization left-hand circularly polarized (LHCP) rejection. The patterns with the vertical feed and shorting pin wires

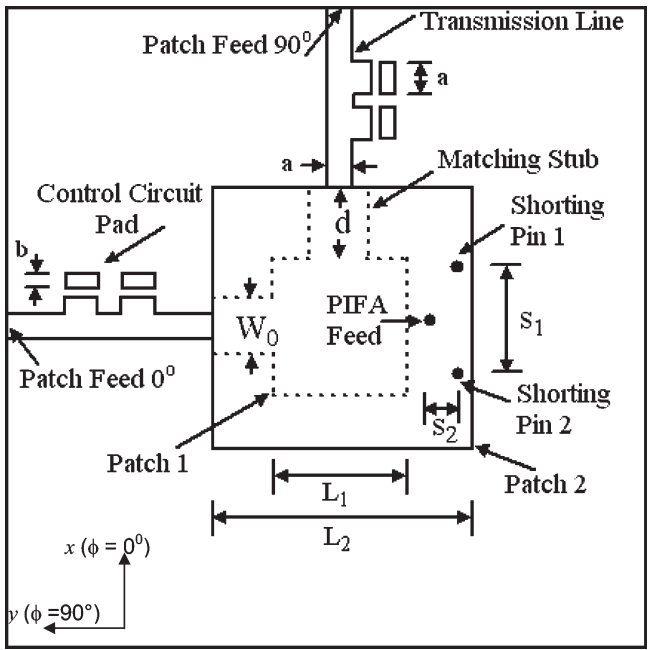

Fig. 12. Simulation model for radiation pattern calculation in HFSS. Parameters: $W_{0}=12 \mathrm{~mm}, a=3.5 \mathrm{~mm}, b=2 \mathrm{~mm}, S_{1}=4 \mathrm{~mm}$, and $S_{2}=1 \mathrm{~mm}$.
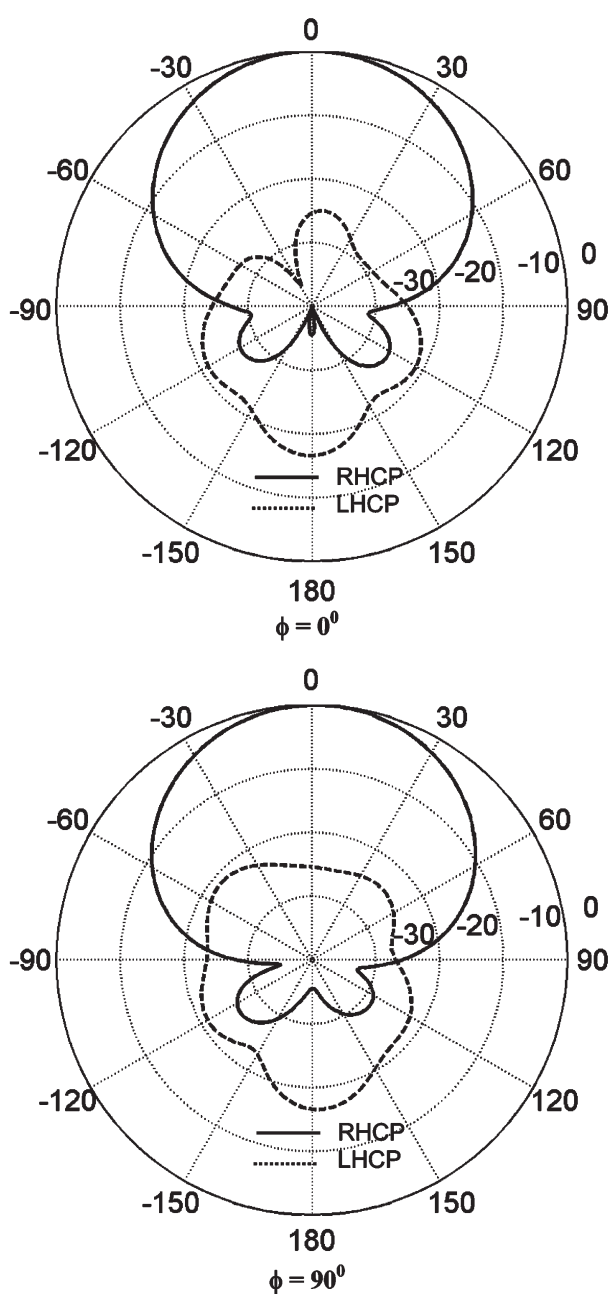

Fig. 13. Computed radiation patterns for the stacked patch antenna at $1.95 \mathrm{GHz}$ (for geometry shown in Fig. 12). Without any switch, vertical PIFA feed or shorting pin wires.

and the connecting pads shown in Fig. 14 are also RHCP and are broadside in nature. The cross-polarized component is suppressed below $10 \mathrm{~dB}$. 

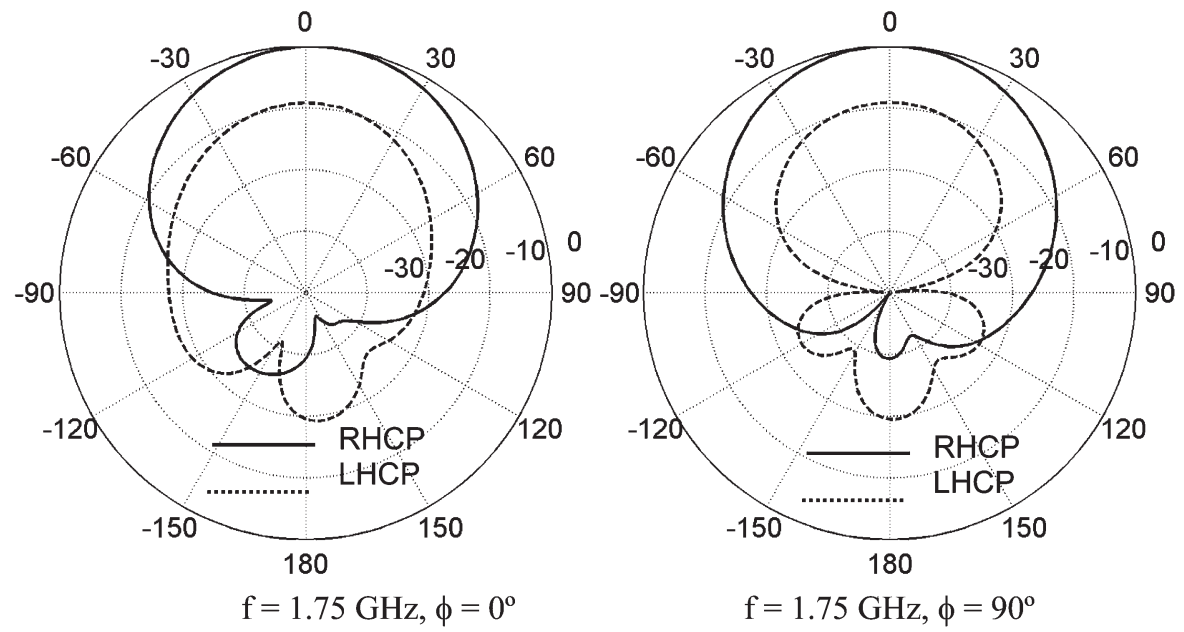

$\mathrm{f}=1.75 \mathrm{GHz}, \phi=0^{\circ}$

$\mathrm{f}=1.75 \mathrm{GHz}, \phi=90^{\circ}$

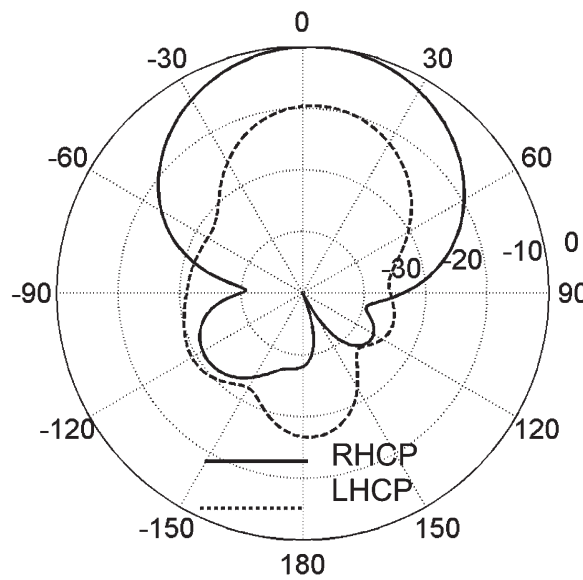

$\mathrm{f}=1.95 \mathrm{GHz}, \phi=0^{\circ}$

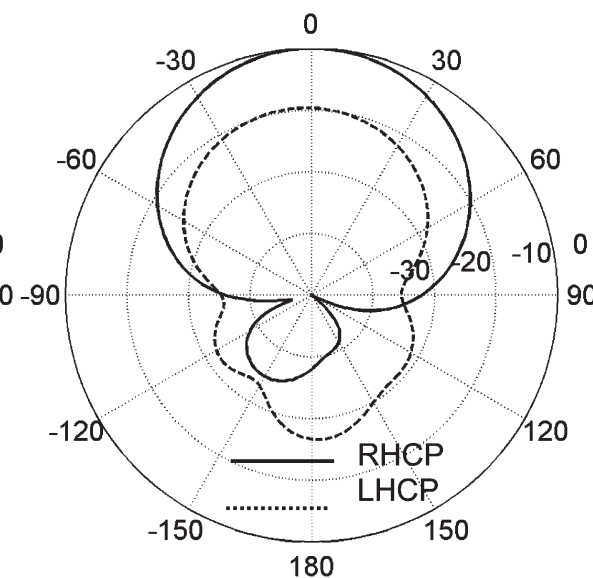

$\mathrm{f}=1.95 \mathrm{GHz}, \phi=90^{\circ}$

Fig. 14. Computed radiation patterns for the stacked patch antenna mode (for geometry shown in Fig. 12). All vertical feed and shorting pin wires for the PIFA mode present. Small 2 by $0.5-\mathrm{mm}$ pad is attached to each vertical wire.

Axial ratio data as a function of frequency for the patch mode are shown in Fig. 15. Clearly, in the absence of the PIFA vertical feed and shorting pin wires and control circuits, the axial ratio performance is excellent. Axial ratio is less than $1 \mathrm{~dB}$. In the presence of the PIFA vertical feed and shorting pin wires and control circuits, the axial ratio is within $3 \mathrm{~dB}$ from 1.6 to $1.84 \mathrm{GHz}(10 \%)$. Note that the measured $2: 1$ VSWR bandwidth extends from 1.665 to $1.95 \mathrm{GHz}(15.8 \%)$. The worst-case axial ratio in the $1.85-1.95 \mathrm{GHz}$ range is $4.2 \mathrm{~dB}$.

The peak gain of the antenna is 7.9-dBi RHCP at $1.75 \mathrm{GHz}$. Gain varies from 7.8 to $7.9 \mathrm{dBi}$ from 1.65 to $1.95 \mathrm{GHz}$. Considering the switch insertion loss in the gain budget will result in a peak gain of 7.5-dBi RHCP, which is still considerably high for many single antenna wireless applications.

\section{PIFA Mode of Operation}

Referring to Fig. 1, when switch 1 is "off" and switches 2 and 3 are "on," the antenna operates in the PIFA regime. In this case, the resonant frequency is primarily determined by patch 2 (top larger patch). The total length plus width of patch 2 is $120 \mathrm{~mm}$. This dimension is approximately a quarter of the wavelength. Thus, the wavelength in this case should be $480 \mathrm{~mm}$ with a corresponding antenna resonant frequency of $625 \mathrm{MHz}$. The tuning of the antenna in the PIFA regime is controlled by the parameter $S_{1} / 2$ (distance between the feed and the shorting pin (see Fig. 12). The measured VSWR data for the PIFA mode of operation are shown in Fig. 15. An inset photograph of this measurement scenario is shown in Fig. 16. The patch mode feed line, switch, and control circuits are intact and attached to patch 1 . Only the patch mode switch bias is not activated. The PIFA mode switch bias is activated to turn both the feed and shorting pin switches (2 and 3) ON. Measured VSWR data clearly demonstrate the operation of the antenna within the frequency range of 585-630 MHz (7.4\% bandwidth). Computed data using HFSS are also shown in Fig. 16 for comparison. The operating frequency for the computed case is $50 \mathrm{MHz}$ higher and the bandwidth narrower. The diodes, the small connecting pads on the board, and the capacitors may be responsible for the discrepancy between the simulated and measured data. Note that in the simulation model, the diodes and capacitors are considered short, and the inductors 


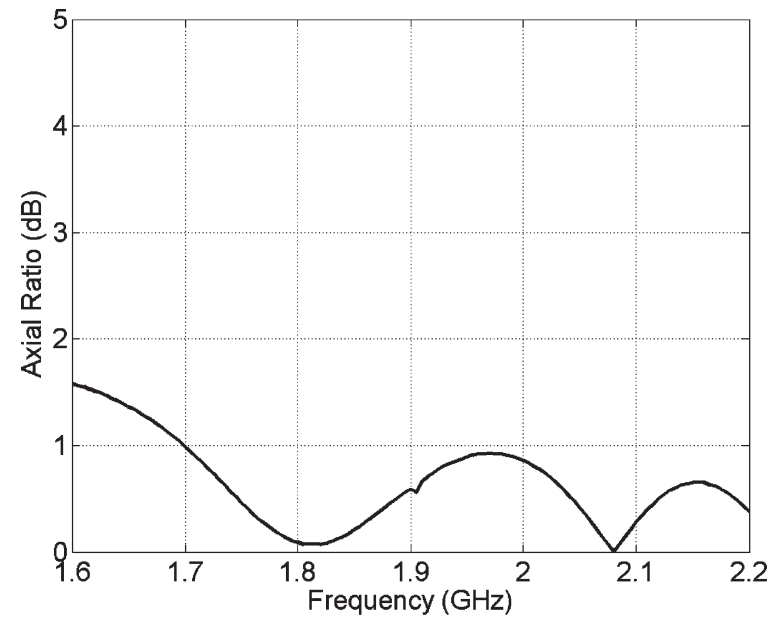

(a)

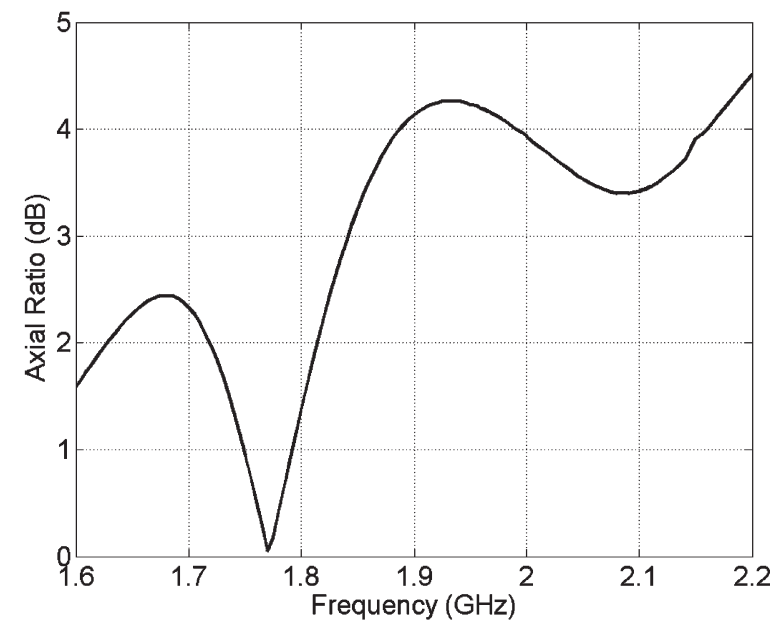

(b)

Fig. 15. Computed axial ratio for the stacked patch antenna mode (for geometry shown in Fig. 12). (a) No PIFA vertical feed shorting pin wires and control circuits. (b) With PIFA vertical feed shorting pin wires and control circuits.

are considered open. The presence of the patch mode feed and control circuits has no effect on the PIFA mode operation since patch 1 is completely shadowed by patch 2 .

Computed radiation patterns for the PIFA are shown in Fig. 17. Patterns were computed using the HFSS, considering the diodes and capacitors as shorts and the inductors as opens for the PIFA mode. The patch mode switch (switch 1 in Fig. 1) was turned "off." Therefore, the diode was open while the capacitors were shorts. For the 130 by $130-\mathrm{mm}$ ground plane, patterns were computed at $674 \mathrm{MHz}$ because that is the frequency where the antenna is resonant (see Fig. 16 computed VSWR). The patterns show very little directionality since the ground plane is only 0.3 by $0.3 \lambda$. The peak gain is $1.3 \mathrm{dBi}$. Increasing the ground plane size to 400 by $400 \mathrm{~mm}(0.9$ by $0.9 \lambda$ ) increases the resonant frequency to $688 \mathrm{MHz}$. Patterns computed at this frequency show a fair amount of directionality with the peak gain increasing to $4.6 \mathrm{dBi}$.

The patterns in the $\phi=0^{\circ}$ plane show that the $E_{\theta}$ component is the dominant component of field with its radiation peak along $\theta=60^{\circ}$. In an ideal infinitely large ground plane case, the

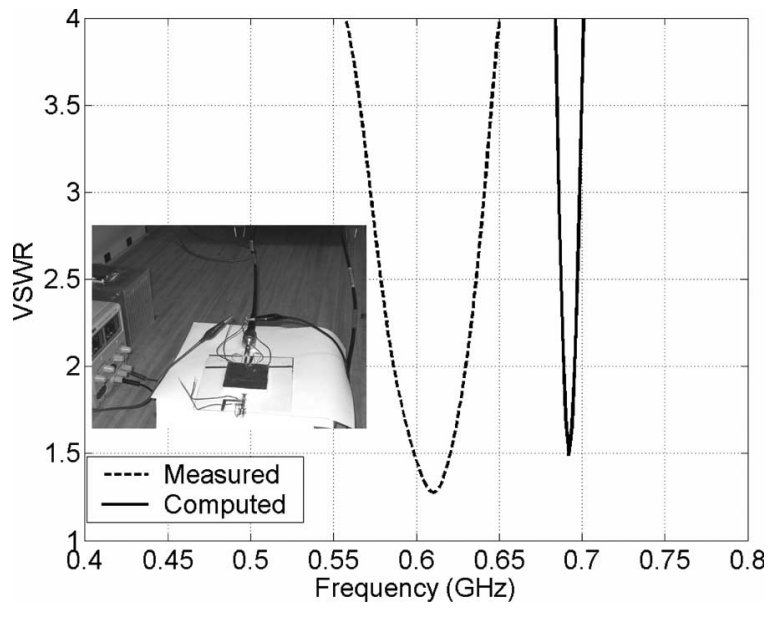

Fig. 16. VSWR versus frequency of the reconfigured PIFA. PIFA mode switches to activate the vertical feed and the shorting pins are activated. Patch switch is unbiased.

beam peak should have been toward $\theta=90^{\circ}$. Due to a finite ground plane, the beam peak is tilted. The antenna shows an $E_{\phi}$ component of field which is directed toward $\theta=0^{\circ}$ but is generally smaller in magnitude. Since in this regime of operation the antenna will be used for nonline-of-sight terrestrial links such as land mobile radio, two polarizations can be useful due to an increased probability of signal strength enhancement due to multipath. The pattern in the $\phi=90^{\circ}$ plane shows similar $E_{\theta}$ characteristics, while the $E_{\phi}$ component is well below $30 \mathrm{~dB}$.

As mentioned, the peak gain of the PIFA at $688 \mathrm{MHz}$ is $4.6 \mathrm{dBi}$. Subtracting the diode insertion loss of $0.7 \mathrm{~dB}$ provides a gain of $3.9 \mathrm{dBi}$ for this mode. In the PIFA regime of operation, the antenna is linearly polarized. The antenna has an excellent upper hemispherical and azimuthal coverage suitable for terrestrial communications. The patterns on the smaller 0.3 by $0.3 \lambda$ ground plane are similar to the patterns of PIFAs for mobile phone applications [22]-[27], while the patterns on the larger 0.9 by $0.9 \lambda$ ground plane are similar to the R-shaped PIFA on a vehicle described in our earlier work [28].

\section{CONCLUSION}

The design of a stacked reconfigurable microstrip patch antenna is presented. Using the $\mathrm{p}-\mathrm{i}-\mathrm{n}$ diode switches, it has been demonstrated that a stacked microstrip antenna can be reconfigured to support two distinctly different operating frequency bands with varying bandwidth, pattern, and polarization requirements. The stacked patch design example presented in this paper at $1.75 \mathrm{GHz}$ has a bandwidth of $11.4 \%$ and 7.5-dBi RHCP peak gain. The antenna is suitable for vehicular satellite communication wherein the antenna can be mounted on the roof and fed using a coaxial line through the roof or the door-jam. When the stacked patch mode is deactivated and the antenna is in the PIFA regime of operation, it can support a linearly polarized terrestrial communication link (615 MHz). The radiation patterns are directed toward the upper hemisphere with a peak gain of $3.9 \mathrm{dBi}$ and strong 


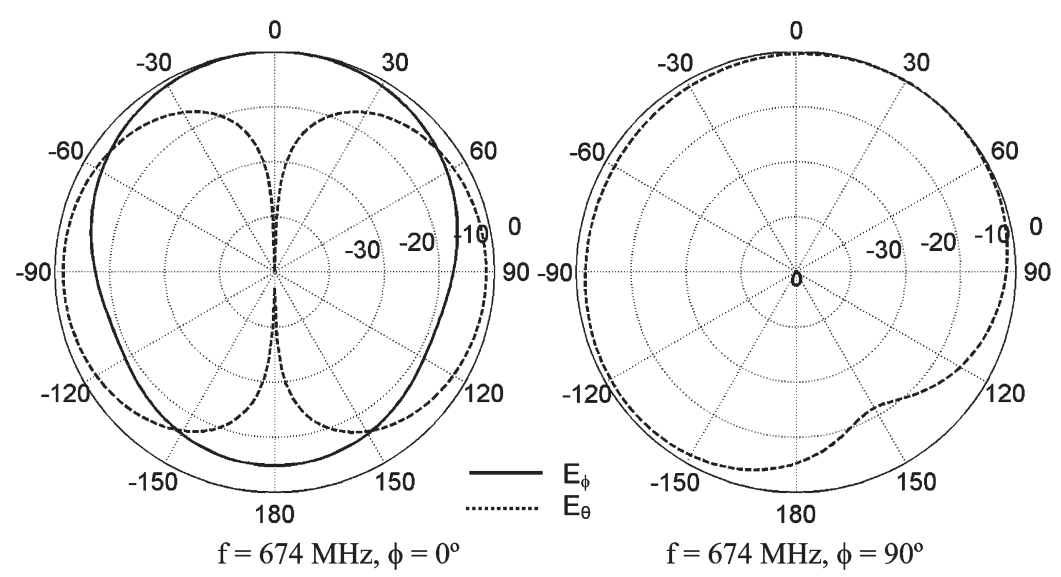

(a)

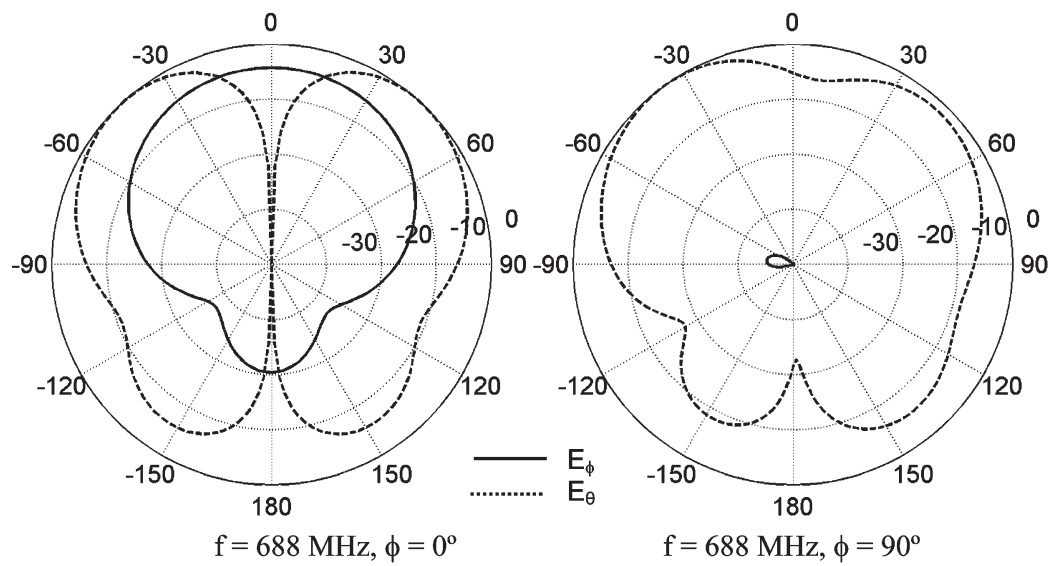

(b)

Fig. 17. Computed radiation patterns of antenna in PIFA regime of operation at $670 \mathrm{MHz}$. (a) 130 by 130 -mm ground plane. (b) 400 by $400-\mathrm{mm}$ ground plane.

azimuthal pattern coverage. Antenna VSWR bandwidth is about $7.4 \%$.

\section{REFERENCES}

[1] W. H. Weedon and W. J. Payne, "MEMS-switched reconfigurable multiband antenna: Design and modeling," in Proc. Antenna Appl. Symp., Monticello, IL, Sep. 15-17, 1999, pp. 203-231.

[2] J.-C. Chiao, Y. Fu, I. M. Chio, M. D. Lisio, and L. Y. Lin, "MEMS reconfigurable vee antenna," in IEEE MTT-S Symp. Dig., 1999, pp. 15151518.

[3] F. Yang and Y. Rahmat-Samii, "Patch antenna with switchable slot (PASS): Dual frequency operation," Microw. Opt. Technol. Lett., vol. 31, no. 3, pp. 165-168, Nov. 2001.

[4] D. Peroulis, K. Sarabandi, and L. P. B. Katehi, "A planar VHF reconfigurable slot antenna," in IEEE Antennas Propag. Symp. Dig., 2001, vol. 1, pp. 154-157.

[5] J. T. Bernhard, R. Wang, and P. Mayes, "Stacked reconfigurable antenna elements for space based radar applications," in IEEE Antennas Propag. Symp. Dig., 2001, vol. 1, pp. 158-161.

[6] F. Yang and Y. Rahmat-Samii, "A reconfigurable patch antenna using switchable slots for circular polarization diversity," IEEE Microw. Wireless Compon. Lett., vol. 12, no. 13, pp. 96-98, Mar. 2002.

[7] L. N. Pringle, P. G. Friedrich, S. P. Blalock, G. N. Kiesel, P. H. Harms, D. R. Denison, E. J. Kuster, T. L. Fountain, and G. S. Smith, "GTRI reconfigurable aperture design," in IEEE Antennas Propag. Symp. Dig., San Antonio, TX, 2002, vol. 1, pp. 473-476.

[8] G. H. Huff, J. Feng, S. Zhang, and J. T. Bernhard, "A novel radiation pattern and frequency reconfigurable single turn square spiral microstrip antenna," IEEE Microw. Wireless Compon. Lett., vol. 13, no. 2, pp. 57-59, Feb. 2003.
[9] J. C. Langer, J. Zou, C. Liu, and J. T. Bernhard, "Micromachined reconfigurable out-of-plane microstrip patch antenna using plastic deformation magnetic actuation," IEEE Microw. Wireless Compon. Lett., vol. 13, no. 3, pp. 120-122, Mar. 2003.

[10] L. Jofre, B. A. Cetiner, and F. De Falviss, "Miniature multi-element antenna for wireless communications," IEEE Trans. Antennas Propag., vol. 50, no. 5, pp. 658-669, May 2002.

[11] N. C. Karmakar, P. Hendro, and L. S. Firmansyah, "Shorting strap tunable single feed dual-band PIFA," IEEE Microw. Wireless Compon. Lett., vol. 13, no. 1, pp. 13-15, Jan. 2003.

[12] N. C. Karmakar, "Shorting strap tunable single feed dual-band stacked patch PIFA," IEEE Antennas Wireless Propag. Lett., vol. 2, no. 2 , pp. 68-71, 2003.

[13] G. H. Huff and J. T. Bernhard, "Integration of packaged RF MEMS switches with radiation pattern reconfigurable square spiral microstrip antennas," IEEE Trans. Antennas Propag., vol. 54, no. 2, pp. 464-469, Feb. 2006.

[14] Ansoft HFSS, Ansoft Corporation. [Online]. Available: http://www. ansoft.com/products/hf/hfss

[15] D. M. Pozar and S. M. Duffy, "A dual-band circularly polarized aperturecoupled stacked microstrip antenna for global positioning satellite," IEEE Trans. Antennas Propag., vol. 45, no. 11, pp. 1618-1625, Nov. 1997.

[16] J. Ollikainen, M. Fischer, and P. Vainikainen, "Thin dual-resonant stacked shorted patch antenna for mobile communications," Electron. Lett., vol. 35, no. 6, pp. 437-438, Mar. 1999.

[17] L. Zaid, G. Kossiavas, J. Dauvignac, J. Cazajous, and A. Papiernik, "Dual-frequency and broadband antenna with stacked quarter wavelength elements," IEEE Trans. Antennas Propag., vol. 47, no. 4, pp. 654-660, Apr. 1999.

[18] R. B. Waterhouse, Microstrip Patch Antennas: A Designer's Guide. Norwell, MA: Kluwer, Jan. 2003. 
[19] J. Anguera, G. Font, C. Puente, C. Borja, and J. Soler, "Multifrequency microstrip patch antenna using multiple stacked elements," IEEE Microw. Wireless Compon. Lett., vol. 13, no. 3, pp. 123-124, Mar. 2003.

[20] D. M. Pozar, Microwave Engineering, 2nd ed. Hoboken, NJ: Wiley, 1998.

[21] Agilent HSMP389B Diode. [Online]. Available: http://www.agilent.com

[22] Z. D. Liu, P. S. Hall, and D. Wake, "Dual-frequency planar inverted-F antenna," IEEE Trans. Antennas Propag., vol. 45, no. 10, pp. 1451-1458, Oct. 1997.

[23] M. Ali, R. A. Sadler, and G. J. Hayes, "A uniquely packaged internal inverted-F antenna for bluetooth or wireless LAN application," IEEE Antennas Wireless Propag. Lett., vol. 1, no. 1, pp. 5-7, 2002.

[24] M. Ali and G. J. Hayes, "A small printed integrated inverted-F antenna for bluetooth application," Microw. Opt. Technol. Lett., vol. 33, no. 5, pp. 347-349, Jun. 5, 2002.

[25] M. F. Abedin and M. Ali, "Modifying the ground plane and its effect on planar inverted-F antennas (PIFAs) for mobile phone handsets," IEEE Antennas Wireless Propag. Lett., vol. 2, no. 15, pp. 226-229, 2003.

[26] M. Z. Azad and M. Ali, "A miniaturized hilbert PIFA for dual band mobile wireless applications," IEEE Antennas Wireless Propag. Lett., vol. 4, no. 1, pp. 59-62, 2005.

[27] M. Ali, "Miniaturized packaged (embedded) antennas for portable wireless devices," in Encyclopedia of RF and Microwave Engineering. Hoboken, NJ: Wiley, Feb. 2005, pp. 3068-3082.

[28] M. Ali, G. Yang, H. S. Hwang, and T. Sittironnarit, "Design and analysis of an R-shaped dual-band planar inverted-F antenna for vehicular applications," IEEE Trans. Veh. Technol., vol. 53, no. 1, pp. 29-37, Jan. 2004.

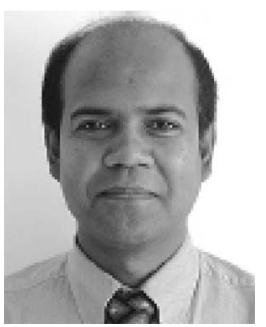

Mohammod Ali (S'93-M'93-SM'04) received the B.Sc. degree in electrical and electronic engineering from Bangladesh University of Engineering and Technology, Dhaka, Bangladesh, in 1987 and the M.A.Sc. and Ph.D. degrees, both in electrical engineering, from University of Victoria, Victoria, BC, Canada, in 1994, and 1997, respectively.

From 1988 to 1992, he was with Bangladesh Institute of Technology, Chittagong, Bangladesh. From January 1998 to August 2001, he was with Ericsson Inc., Research Triangle Park, NC, first as a Staff Engineer and then as a Senior Staff Engineer. Since August 2001, he has been with the Department of Electrical Engineering, University of South Carolina, Columbia, where he is currently an Assistant Professor. He had also held appointments as a Visiting Research Scientist with the Motorola Corporate EME Research Laboratory, Plantation, FL, from June to August of 2004. He has authored/coauthored of over 80 refereed journals and conference publications and holds five U.S. patents. His research interests include miniaturized packaged (embedded) antennas, meta materials and their antenna applications, distributed wireless sensors and rectennas, reconfigurable antennas, and portable/wearable antennas and their interactions with humans (SAR).

Dr. Ali is the recipient of the 2003 National Science Foundation Faculty Career Award.

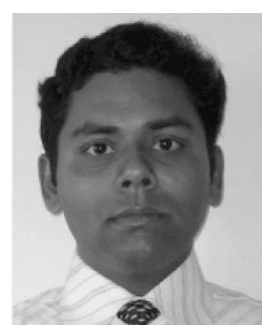

Abu T. M. Sayem (S'05) received the B.Sc. degree in electrical and electronic engineering from Bangladesh University of Engineering and Technology (BUET), Dhaka, Bangladesh, in September 1999. Since August 2003, he has been working toward the $\mathrm{Ph} . \mathrm{D}$. degree in electrical engineering at the University of South Carolina, Columbia.

From February to October of 2000, he worked with the Ekushey Television Ltd., Dhaka. From November 2000 to August 2003, he worked with the GrameenPhone Ltd., Dhaka, as an RF Engineer. His current research interests include miniature antennas, ultrawideband antennas, specific absorption rate (SAR), and bioelectromagnetics. He has authored/coauthored several conference papers and one book chapter.

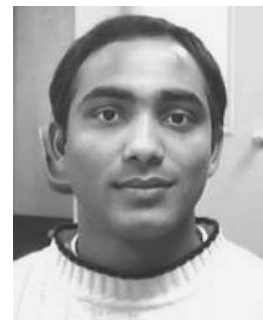

Vijay K. Kunda received the B.S. degree in electronics and communications engineering from Vasavi College of Engineering, Hyderabad, India, in 2001 and the M.S. degree in electrical engineering from the University of South Carolina, Columbia, in 2004 .

In August 2002, he was with the University of South Carolina as a Research Assistant, where he was involved in designing WLAN packaged antennas for laptop and reconfigurable antennas for multiple applications. From June 2005 to February 2006, he worked as a Signal Integrity Engineer with Stratus Technologies, Boston, MA, where he helped the team in developing the design rules for the faulttolerant server board. In March 2006, he moved to SUN Microsystems, Burlington, MA, where he is currently working on the design rules for the FBDIMM memory bus on the SUN server boards. His research interests include antenna design and RF circuit design along with signal integrity. He has three conference papers and a journal publication in antenna design. 